\title{
A Simple Approach in Estimating the Effectiveness of Adapting Mirror Concentrator and Tracking Mechanism for PV Arrays in the Tropics
}

\author{
M. E. Ya'acob, ${ }^{1}$ H. Hizam, ${ }^{1,2}$ H. Abdul Rahman, ${ }^{3}$ W. Z. Wan Omar, ${ }^{3}$ \\ Myo Than Htay, ${ }^{4}$ and A. H. M. A. Rahim ${ }^{5}$ \\ ${ }^{1}$ Department of Electrical \& Electronic Engineering, Faculty of Engineering, Universiti Putra Malaysia, \\ 43400 Serdang, Selangor, Malaysia \\ ${ }^{2}$ Centre of Advanced Power and Energy Research (CAPER), Universiti Putra Malaysia, 43400 Serdang, Selangor, Malaysia \\ ${ }^{3}$ Centre of Electrical Energy Systems, Universiti Teknologi Malaysia, 81310 Johor Bahru, Malaysia \\ ${ }^{4}$ Department of Electrical and Electronic Engineering, Faculty of Engineering, Shinshu University, Nagano 380-8553, Japan \\ ${ }^{5}$ Department of Electrical Engineering, King Fahd University of Petroleum \& Minerals, P.O. Box 349, Dhahran 31261, Saudi Arabia
}

Correspondence should be addressed to M. E. Yảacob; fendyupm@gmail.com

Received 25 November 2013; Revised 16 April 2014; Accepted 12 May 2014; Published 2 June 2014

Academic Editor: Hui Shen

Copyright (C) 2014 M. E. Ya'acob et al. This is an open access article distributed under the Creative Commons Attribution License, which permits unrestricted use, distribution, and reproduction in any medium, provided the original work is properly cited.

\begin{abstract}
Mirror concentrating element and tracking mechanism has been seriously investigated and widely adapted in solar PV technology. In this study, a practical in-field method is conducted in Serdang, Selangor, Malaysia, for the two technologies in comparison to the common fixed flat PV arrays. The data sampling process is measured under stochastic weather characteristics with the main target of calculating the effectiveness of PV power output. The data are monitored, recorded, and analysed in real time via GPRS online monitoring system for 10 consecutive months. The analysis is based on a simple comparison of the actual daily power generation from each PV generator with statistical analysis of multiple linear regression (MLR) and analysis of variance test (ANOVA). From the analysis, it is shown that tracking mechanism generates approximately 88 Watts $(9.4 \%)$ compared to the mirror concentrator which generates 144 Watts (23.4\%) of the cumulative dc power for different array configurations at standard testing condition (STC) references. The significant increase in power generation shows feasibilities of implying both mechanisms for PV generators and thus contributes to additional reference in PV array design.
\end{abstract}

\section{Introduction}

In this work, the main target is to increase the daily energy generation from PV generators despite the fluctuating sun irradiance, $G$, which is the sole source of photonic effect in PV electricity conversion process. Research works around the globe were conducted to improve the energy production of solar PV modules under real operating conditions. Chen [1] reported that the installed capacity of the PV in Malaysia at the end of 2009 and 2010 is $1 \mathrm{MWp}$ and $100 \mathrm{MWp}$, respectively. The potential Malaysian uptake of solar PV is set to increase with the estimated requirement of up to $6500 \mathrm{MW}$ by 2030 [1]. Market research also pointed that solar PV would have the biggest share of Malaysia renewable energy installations as the price of solar PV keeps going down. This is mainly due to technology maturity and economies of scale as more solar cell manufacturers come online.

The Government of Malaysia had officially started the fit-in-tariff (FiT) enactment of the renewable energy law on December 1, 2011, to encourage uptake of renewable energy projects in the country. In this scheme, solar PV received the highest FiT rate of up to RM1.77 per kWh energy production for projects approved in 2012. This rate is applicable for 21year contract period. The rate for new projects will reduce by $8 \%$ per year, depending on the approval date of the project [2].

The local condition and environment at the targeted location for the application of the PV varies. This affects the 
generation capability and the efficiency of the PV modules, which are generally calculated and solely extrapolated by per PV module characteristics, which are obtained from standard tests in the laboratory [3]. The energy generation quantity is not included, as this would depend on the duration of the sunshine and the quality of the sunlight incident onto the PV panel [4]. To increase the capability of the solar cells, solar tracking and solar light concentrations could be employed individually or in combination. Solar tracking basically employs mechanism that continually points the PV modules directly to the sun [5].

Mirror concentrating element and tracking mechanism has been seriously investigated and widely adapted in solar PV technology. In this study, a practical in-field method is conducted in Serdang, Selangor, Malaysia, by means of installing multiple solar systems: the first employing the 2-axis sun tracking system, the second employing mirror concentrating system, and the third employing a basic fixed system, a base system, to be used as comparator [6]. The mirror concentrator embedded in the $2 \times \mathrm{CPV}$ technologies adopted V-through concept of configuration with enhancement in mirror concentration. Recent study by [7-11] which implies and enhances the optical efficiency of V-through technology in solar PV application creates alternative means of reducing the overall built-up area, quantity of module, and heat dissipation and thus significantly lowers down the installation cost. Climatic variables in most of the tropical based countries have significant effects on PV performance in generating sufficient and stabilized electricity to the normal grid [12-14] where radiation level $(G)$ and temperature element $(T)$ are the dominant factors in most of the PV efficiency calculations.

The duration of data sampling process is done for 10 consecutive months in the equatorial sun-belt region of uniform temperature-irradiance, high humidity-rainfall, and generally light wind weather characteristics. The data are monitored, recorded, and analysed in real time via general packet radio service (GPRS) which can be managed online via smart-pv.net. The analysis is based on standard testing conditions (STC) data per unit array generation where power contributions from mirror reflecting elements and tracking mechanism are practically analyzed. The STC, as defined in MS/IEC 61836 standards for the photovoltaic technology, reflects the reference values of the in-plane irradiance $(G)$ of $1000 \mathrm{~W} / \mathrm{m}^{2}$, PV cell junction temperature of $25^{\circ}$, and air mass (AM) of 1.5 value to be used during the quality testing of any PV device. A high quality, safe, and durable PV module delivers the expected rated power $\left(W_{p}\right)$ withstanding extremely wide range of environmental conditions and is reputedly capable of delivering high energy yield over a period of time.

Statistical analysis applied for this work is multiple linear regression (MLR) by means of modelling the relationship between two or more explanatory variables. In this case the output power $\left(P_{\mathrm{dc}}\right)$ with the contributions from mirror and tracker element by fitting a linear equation to the observed data with the hypothesis of every value of the independent variable $x_{1}, x_{2}$ is associated with the dependant variable $y$.
The common model for MLR with $n$ given observations can be denoted by

$$
y_{i}=\beta_{0}+\beta_{1} x_{i 1}+\beta_{2} x_{i 2}+\varepsilon_{i} \text { for } i=1,2, \ldots n \text {. }
$$

The MLR technique observes the varying value of $y_{i}$ by expressing the overall correlation as data $=$ fit + residual, where the $\beta$ represents the fit terminology and the $\varepsilon$ for the residual or deviations of the observed and mean values of $y_{i}$. By adapting the analysis of variance (ANOVA) fitting model to the data sets, the analytical process of comparing the mean response values at different levels of the factor is simulated where the program computes a number of means and variances, dividing two variances and comparing the ratio to a handbook value to determine statistical significance $[15,16]$. Each level of the factors is investigated to see if the response is significantly different from the response at other levels of the factor. The ANOVA provides a statistical test of whether or not the means of several groups are equal and therefore generalizes $t$-test to more than two groups for statistical significance. Some practical examples of ANOVA modelling for solar PV application are described in [17-20].

This paper reports the efforts by the authors to practically calculate the effectiveness of solar tracking and mirror based solar concentrating mechanism for electricity generation via simple comparison of recorded field data, where this information will be the additional reference in designing a $\mathrm{PV}$ array configuration installed in the tropics.

\section{PV Pilot Plant Setup}

The entire PV array installed at the site is connected directly to the nearest grid point (Feeder Pillar) which is linked to the main distribution board (MDB) for electricity distribution. The three different PV arrays are configured as shown in Figure 1 where each module is a series of $95 \mathrm{~W}$ CEEG monocrystalline modules with $17.05 \%$ practical conversion efficiency and the specifications are described in Table 1.

The air mass (AM) is the relative optical path length which light takes through the atmosphere normalized to the shortest possible path length with consideration of environmental blockage such as dust and particles. The site calculation is based on (2) with three time intervals of $9 \mathrm{am}$, 12 noon, and $3 \mathrm{pm}$ for the duration of 7 days and projects the value of AM 1.4 or approximately $45^{\circ} \mathrm{C}$ solar zenith angle comparable to air mass AM 1.5 global hemispherical defined by ASTM and IEC. Consider

$$
\mathrm{AM}=\left[1+\left(\frac{s}{h}\right)^{2}\right]^{0.5}
$$

where $s$ is the shadow length and $h$ is the object height.

DC power (in Watt) is calculated directly from PV array generation via online monitoring system http://www.smart-pv.net which adapts cloud database through general packet radio service (GPRS) on $3 \mathrm{G}$ cellular communication with global system for mobile communications. PV generator efficiency is calculated using 
TABLE 1: Specifications of $1 \mathrm{kWp}$ PV generator system.

\begin{tabular}{lll}
\hline Fixed Flat PV (FF) & Tracking flat PV (TF) & Concentrating PV (CPV) \\
\hline (i) Common flat PV array & (i) Dual-axis sun tracking & (i) Dual-axis sun tracking with mirror concentrator \\
(ii) Series connecting 12 units of CEEG & (ii) Series connecting 12 units of CEEG & (ii) Series connecting 6 units of CEEG 95 W \\
$95 \mathrm{~W}$ monocrystalline module & $95 \mathrm{~W}$ monocrystalline module & monocrystalline module \\
(iii) Built-up area: $3.6 \mathrm{~m} \times 2.4 \mathrm{~m}$ & (iii) Built-up area: $3.6 \mathrm{~m} \times 2.4 \mathrm{~m}$ & (iii) Built-up area: $3.6 \mathrm{~m} \times 2.4 \mathrm{~m}$ \\
(iv) Rated power: $1 \mathrm{~kW}$ & (iv) Rated power: $1 \mathrm{~kW}$ & (iv) Rated power: $1 \mathrm{~kW}$ \\
(v) $V_{\mathrm{oc}}: 22.5 \mathrm{~V} \times 12=270 \mathrm{~V}_{\mathrm{dc}}$ & (v) $V_{\mathrm{oc}}: 22.5 \mathrm{~V} \times 12=270 \mathrm{~V}_{\mathrm{dc}}$ & (v) $V_{\mathrm{oc}}: 22.5 \mathrm{~V} \times 6=135 \mathrm{~V}_{\mathrm{dc}}$ \\
(vi) $I_{\mathrm{sc}}: 5.56 \mathrm{~A}_{\mathrm{dc}}$ & (vi) $I_{\mathrm{sc}}: 5.56 \mathrm{~A}_{\mathrm{dc}}$ & (vi) $I_{\mathrm{sc}}: 5.56 \mathrm{~A} \mathrm{~A}_{\mathrm{dc}}$ \\
(vii) $P_{\mathrm{dc}}: 1.5 \mathrm{~kW}$ (rated at STC) & (vii) $P_{\mathrm{dc}}: 1.5 \mathrm{~kW}$ (rated at STC) & (vii) $P_{\mathrm{dc}}: 0.75 \mathrm{~kW}$ (rated at STC) \\
\hline
\end{tabular}

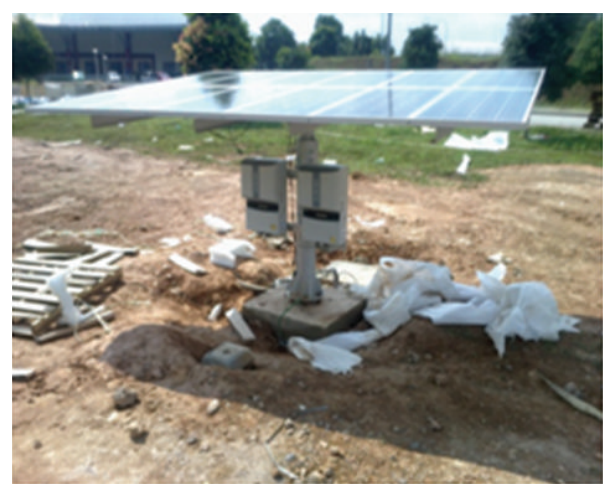

Fixed flat (configured using 12 CEEG modules of $95 \mathrm{~W}$ )

(a)

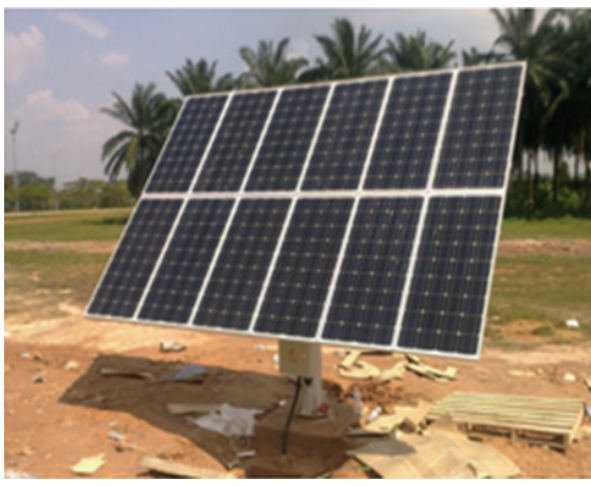

Tracking flat (configured using 12 CEEG modules of $95 \mathrm{~W}$ )

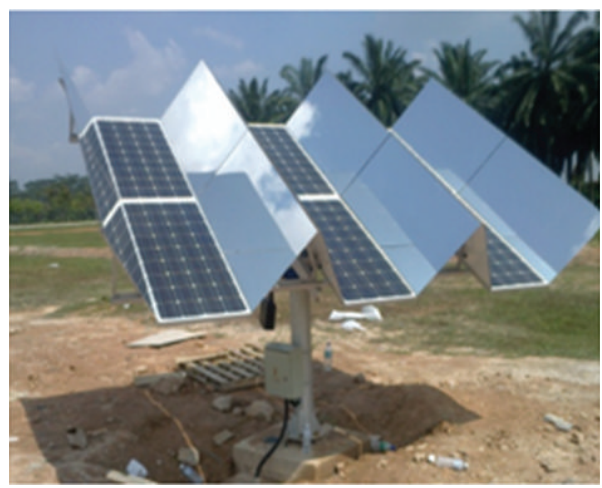

2x CPV (configured using 6 CEEG modules of $95 \mathrm{~W}$ )

(c)

FIGURE 1: Overview of 3 types of PV generators installed at site.

(3) by implying factors of irradiation $(G)$ and area $(A)$ where the built-up area is $8.64 \mathrm{~m}^{2}$ as follows:

$$
\eta_{\text {gen }}=100 *\left[\frac{P}{(G * A)}\right]
$$

The standard calculation for DC power is calculated using (4) where the values are based on the different types of PV arrays to produce the individual power outcome. The main element of calculating the contributions from mirror and tracking elements is done by means of a simple comparison of the recorded power output based on the actual data at site. Power from mirror concentrator $\left(P_{m}\right)$ is calculated using (5) and power from tracking mechanism $\left(P_{t}\right)$ is calculated using (6). Consider

$$
\begin{gathered}
P_{\mathrm{dc}}=I_{\mathrm{dc}} \times V_{\mathrm{dc}} \\
P_{m}=P_{\mathrm{CPV}}-P_{\mathrm{TF}} \\
P_{t}=P_{\mathrm{TF}}-P_{\mathrm{FF}} .
\end{gathered}
$$

For (4) and (5), the ground condition during data sampling is the same at exact time sequence and is applying the same CEEG PV module specifications. For (6), the amount of PV module should be the same and as the tracking flat occupies twelve PV modules compared to the CPV which is configured 


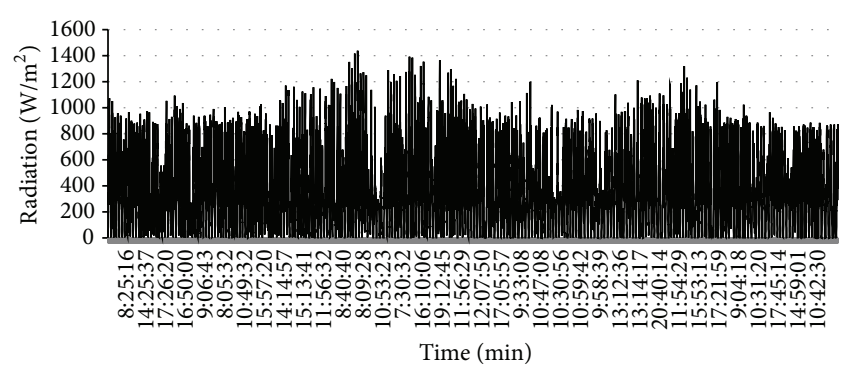

FIGURE 2: Radiation profile for 12,190 samples of field data.

using only six PV modules the approach is to divide $P_{\mathrm{TF}}$ with 2.

The data for three environment factors of radiation $(G)$, wind speed $(w)$, and ambient temperature $\left(T_{a}\right)$ are captured and logged using 3-parameter weather station installed at site.

\section{Results and Discussion}

The radiation profile (in $\mathrm{W} / \mathrm{m}^{2}$ ) shown in Figure 2 is plotted for the whole monitoring period of 268 days operation with 12,190 data samples. The highest radiation level recorded during the sampling period was at $1438 \mathrm{~W} / \mathrm{m}^{2}$ on 15 May 2012. The sun hours throughout the monitoring period are calculated at 3047.5 hours with 11.34 hours/day of sun radiation received which is relatively high and thus supports the 6 hours of direct sun each day all year round as claimed by Chen [1]. Figure 2 also indicates the time scale in $x$-axis (the time sequence of daily sun received at site) where if we segment the sun hours into 3 segments of 4 hours segment 2 (10.00 am to $2.00 \mathrm{pm}$ ) shows the highest radiation values compared to segment 1 (6.00 am to $10.00 \mathrm{am})$ and segment $3(2.00 \mathrm{pm}$ to $6.00 \mathrm{pm})$. The minimum recorded radiation started at the value of $3 \mathrm{~W} / \mathrm{m}^{2}$ as early as 4.00 am for most of the days. The average radiation recorded for 15 -minute interval during generation days is $339.7 \mathrm{~W} / \mathrm{m}^{2}$.

The high value of radiation level at site is further supported based on the 2012 annual reports by the Meteorological Department of Malaysia where the mean daily global radiation was reported ranging from $16 \mathrm{MJ} / \mathrm{m}^{2}$ to $23 \mathrm{MJ} / \mathrm{m}^{2}$ as plotted in Figure 3.

From the report, it can be interpolated that the PV pilot plant in Universiti Putra Malaysia (UPM) receives a strong solar radiation of $17-18 \mathrm{MJ} / \mathrm{m}^{2}$ or $4.72-5 \mathrm{kWh} / \mathrm{m}^{2}$ daily. Haris $[21,22]$ supports this statement with yearly average global irradiance value of $1571 \mathrm{kWh} / \mathrm{m}^{2}$ or $4.3 \mathrm{kWh} / \mathrm{m}^{2}$ daily for Kuala Lumpur which is the closest reference to the project site. Figures 4 and 5 illustrate the ambient temperature $\left(T_{a}\right)$ and wind speed $(w)$ pattern at site throughout the monitoring period of 15-minute time intervals.

The recorded ambient temperature ranges from $22.2^{\circ} \mathrm{C}$ up to $38.4^{\circ} \mathrm{C}$ with an average value of $29.41^{\circ} \mathrm{C}$, while wind speed flows from $0 \mathrm{~m} / \mathrm{s}$ up to $8.9 \mathrm{~m} / \mathrm{s}$ with average value of $1.27 \mathrm{~m} / \mathrm{s}$. The wind profile is not very strong at the site due to the experience of having $0 \mathrm{~m} / \mathrm{s}$ (no wind) for about 527 hours or 22 days throughout the monitoring period.

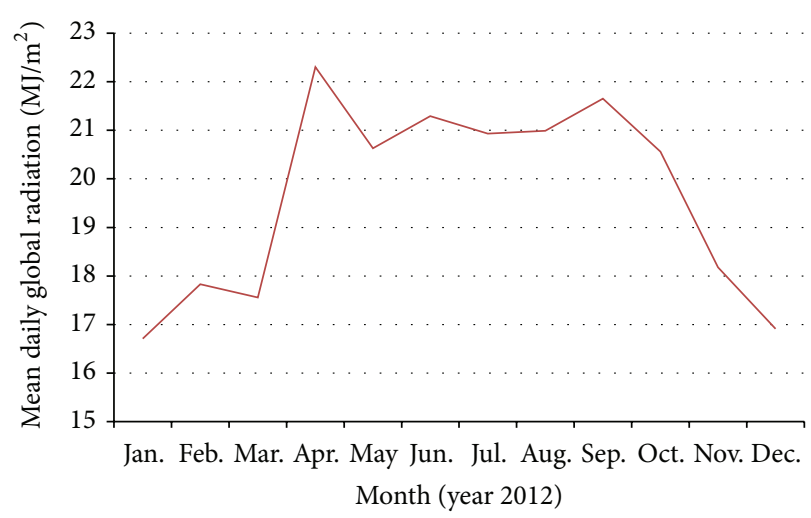

FIGURE 3: Monthly mean ambient temperature and mean daily global radiation for the year 2012 at KLIA, Sepang, Malaysia.

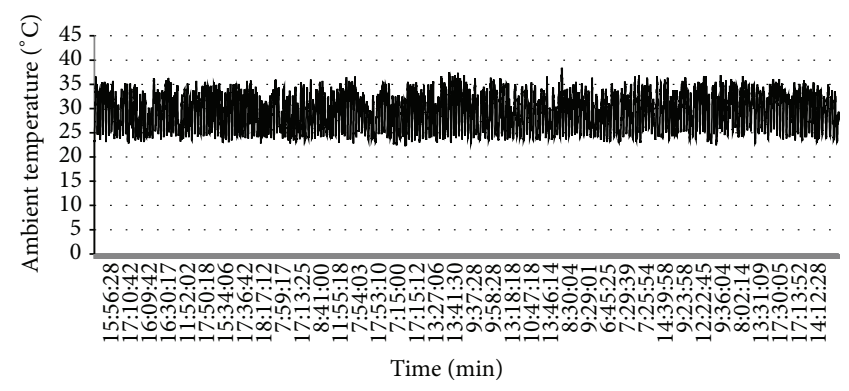

FIGURE 4: Ambient temperature pattern for 10 months.

The PV generator efficiency as in (3) is plotted as shown in Figure 6. From this calculation, the average values for 117 samples of data show that FF generator achieves efficiency of $10.04 \%$ and TF generator produces up to $10.78 \%$ which is the highest and the lowest efficiency value coming from CPV generator with $3.04 \%$. In general, it can be denoted that the $\eta_{\text {gen }}$ value contradicts the rated CEEG PV module efficiency of $17.05 \%$.

As means of analysing mirror and tracker contribution, the power generation (in kilowatt) from mirror concentrator and tracking mechanism is plotted in Figure 7 for 62 data samples of standard testing conditions (STC) with 5\% tolerance based on field measurement. Based on the field data collected, the ANOVA test as described in Table 2 is further calculated as statistical justification on the reliability of sample data used and to show correlation values of the mirror and tracker contribution. In this case, the CPV generator energy output $\left(P_{\mathrm{dc}}\right)$ is used as the dependent variable $(y$ parameter) as the generator has both mirror and tracking mechanism features. The mirror and tracking mechanism are classified as the independent variable ( $x$-parameter).

At a sample time interval, the highest recorded power generated is from TF generator for $1.27 \mathrm{~kW}$ followed by $1.05 \mathrm{~kW}$ from FF generator and the least from CPV generator of $0.63 \mathrm{~kW}$ where the power generation heavily depended on the quantity of PV modules applied in each generator.

From the plotted data in Figure 8 and (4)-(6), the results showed that, for this site (Serdang, Malaysia), it is found that 
TABLE 2: Summary output of MLR and ANOVA.

(a)

\begin{tabular}{lc}
\hline & Regression statistics \\
\hline Multiple $R$ & \\
$R$ square & 0.667607 \\
Adjusted $R$ square & 0.4457 \\
Standard error & 0.42691 \\
Observations & 0.062748 \\
\hline
\end{tabular}

(b)

\begin{tabular}{lccccc}
\hline & & \multicolumn{3}{c}{ ANOVA } & \multicolumn{1}{c}{ Sig $F$} \\
\hline Regression & df & SS & MS & 23.72025 & $2.7573 E-08$ \\
Residual & 2 & 0.186789 & 0.093395 & \\
Total & 59 & 0.232303 & 0.003937 & \\
\hline
\end{tabular}

(c)

\begin{tabular}{lcccccc}
\hline & Coef & S.E & $t$ Stat & $P$-value & Lower 95\% & Upper 95\% \\
\hline Intercept & 0.441245 & 0.026579 & 16.60135 & $6.63 E-24$ & 0.38806074 & 0.494429 \\
Tracker contribution & 0.216826 & 0.076519 & 2.833624 & 0.00629 & 0.06371174 & 0.369939 \\
Mirror contribution & 1.078696 & 0.164241 & 6.56777 & $1.45 E-08$ & 0.75005068 & 1.407341 \\
\hline
\end{tabular}

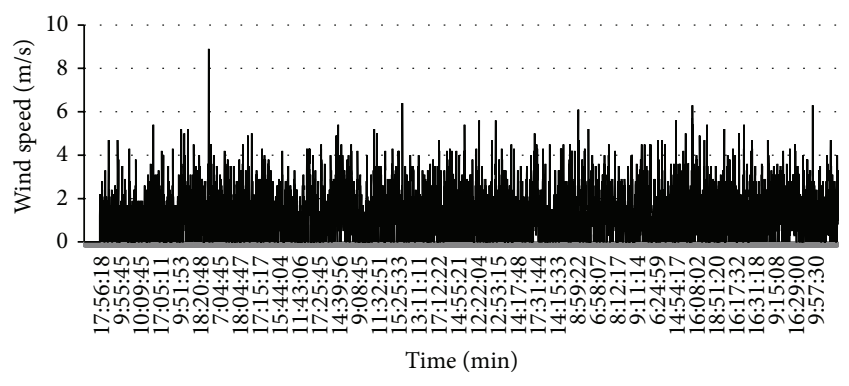

FIGURE 5: Wind profile throughout the monitoring period.

the dual-axis tracking mechanism generates approximately 88 Watts/day or $9.4 \%$ of the TF cumulative power (with the FF generator as reference). The total generation throughout the sampling period coming from tracking mechanism reaches $5.49 \mathrm{~kW}$ out of the recorded $58.5 \mathrm{~kW}$ power output. The tracker generation seems unstable and sometimes experiencing rapid fluctuation mainly due to the sun angle of incident (AOI) and cloud shading factor. The mirror concentrating element generates approximately $8.93 \mathrm{~kW}$ out of $38.2 \mathrm{~kW}$ total power generation from CPV generator (with TF generator as reference). Based on daily average, the value can be converted as 144 Watts/day or $23.4 \%$ of the CPV cumulative power.

The increase of $14 \%$ in power generation shows significant feasibility of implying mirror concentrator for PV generators with temperature increase within the allowable temperature range $\left(-40^{\circ} \mathrm{C}\right.$ to $\left.+85^{\circ} \mathrm{C}\right)$ for the CEEG PV module. The crux finding of this work is statistically supported by means of MLR and ANOVA test. The power generation from mirror reflector is more stable and consistent compared to the tracking mechanism as shown in the line fit plot figures. General

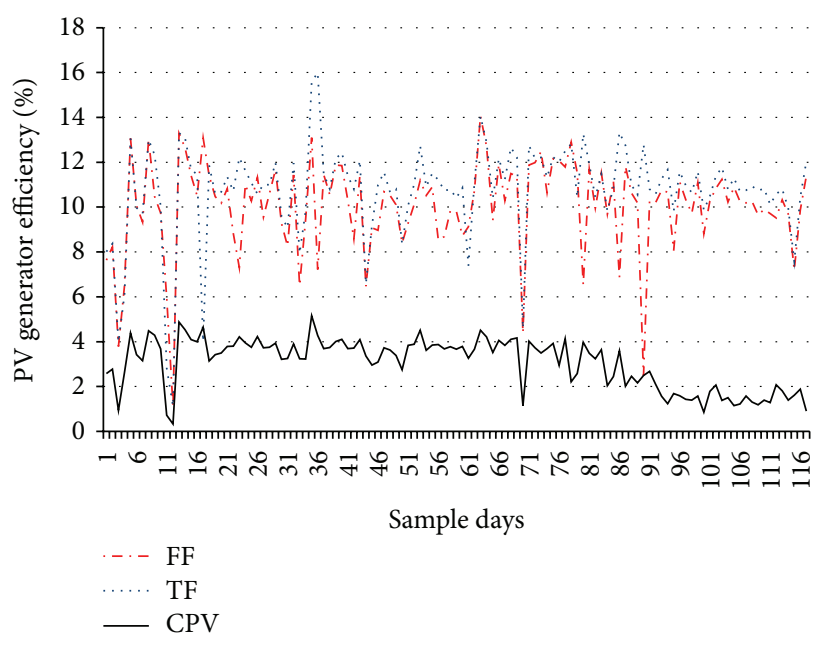

Figure 6: PV generator efficiency based on sampled field data.

observation suggests that the high generation from mirror reflector is due to the increase of incident light reflection on the PV module surface which would also increase the PV surface temperature.

Based on the statistical output, the correlation and coefficients involved are described in (7) with quite a low value standard error (SE) of $0.062 \%$ and sum of squared error (SSE) of $0.42 \%$. The significance of correlations $\left(R^{2}\right)$ between each factor is rather small with 0.45 values but this can be considered enough for statistical correlation based on the good F-test outcomes. Consider

$$
P_{\mathrm{dc}}=0.44+0.22 * P_{m}+1.07 * P_{t} \quad R^{2}=0.45 \text {. }
$$




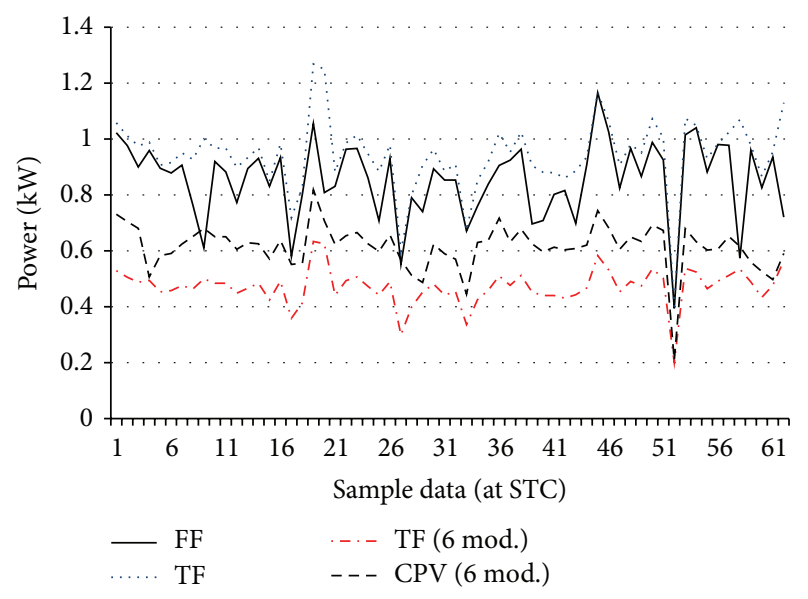

FIgure 7: Power generation from each individual PV generator at STC conditions.

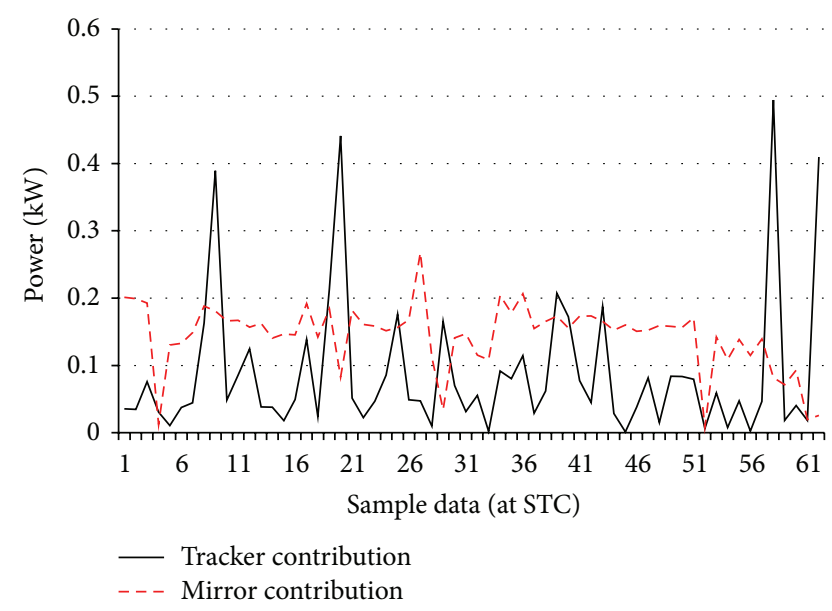

FIGURE 8: Power generation from mirror concentrator and tracking mechanism at site.

This study focuses on the comparison of power generation via adapting mirror concentrator and tracking mechanism on PV arrays with statistical approach using MLR and ANOVA as means of early findings based on the tropical pattern of Malaysia climate.

\section{Conclusion}

The drawbacks of presently practised method of adapting mirror concentrator and tracking mechanism for solar PV generator are analyzed for their genuine daily power contributions specifically in the tropical-ground conditions of Malaysia. PV generator systems rated at $1 \mathrm{~kW}$ with multiple configurations are taken as relative comparison for the sampling period of 10 consecutive months. Analysis shows that the mirror contribution is relatively high compared to the tracking mechanism with $14 \%$ daily increment and has a significant impact on the surface temperature of PV modules. The daily power increase by adapting both enhancement techniques carries strong wattage of adapting PV technology in the tropics.

\section{Nomenclature}

STC: Standard testing condition $\left(G=1000 \mathrm{~W} / \mathrm{m}^{2}, T_{a}=25^{\circ} \mathrm{C}, \mathrm{AM}=1.5\right)$

IEC: International Electrotechnical Commission

ASTM: American Society for Testing and Materials

NOCT: Nominal operating cell temperature

T: $\quad\left(G=800 \mathrm{~W} / \mathrm{m}^{2}, T_{a}=20^{\circ} \mathrm{C}, \mathrm{AM}\right.$ $(\theta+273.15 \mathrm{~K})$

$T_{a}: \quad$ Ambient temperature

$G_{\text {mea }}: \quad$ Measured solar irradiance (based on Pyranometer output)

$P_{\text {rated }}: \quad$ Rated power for PV modules/generator

$P_{\mathrm{mpp}}:$ Output power at maximum power point

$I_{\mathrm{mpp}}$ : Current value at maximum power point

$V_{\mathrm{mpp}}: \quad$ Voltage value at maximum power point

$v: \quad$ Wind speed $(\mathrm{m} / \mathrm{s})$

$\eta: \quad$ Efficiency

$A_{\mathrm{PV}}: \quad$ Aperture surface area of PV module $\left(\mathrm{m}^{2}\right)$

$s: \quad$ Length of shadow

$h$ : $\quad$ Length of object

FF: $\quad$ Fixed flat PV generator

TF: $\quad$ Tracking flat PV generator

$\mathrm{CPV}$ : Concentrating PV generator.

\section{Conflict of Interests}

The authors affirm that the paper has been prepared in accordance with Instructions to Authors, that it has not been previously published, and that they have neither conflict of interests nor financial interests in the energy industry or any other institutional bodies.

\section{Acknowledgments}

The authors thank Sichuan Zhonghan Solar Power Co. Ltd. for the generous support throughout this project period. Furthermore, the authors delegate their thanks to the Research Management Centre (RMC), Universiti Putra Malaysia, for the approval of research funding under the Project Matching Grant (Vote no. 9300400) and Ministry of Higher Education, Malaysia, for the approval of Exploratory Research Grant Scheme (ERGS Vote no. 5527132).

\section{References}

[1] W. N. Chen, "Solar photovoltaic-plug into the sun-part 1," in MGCC Quarterly, pp. 10-12, Malaysia-German Chamber of Commerce and Industry, Kuala Lumpur, Malaysia, 2010.

[2] Anon, "Sustainable Energy Development Authority Malaysia FiT Dashboard," April 2013, http://seda.gov.my/. 
[3] A. International, ASTM E948-09 Standard Test Method for Electrical Performance of Photovoltaic Cells Using Reference Cells under Simulated Sunlight, ASTM International, West Conshohocken, Pa, USA, 2009.

[4] H. Abdul Rahman, Energy analysis based on simulation model for building integrated photovoltaic system for Malaysia [Ph.D. thesis], Faculty of Electrical Engineering, Universiti Teknologi Malaysia, Johor Bahru, Malaysia, 2012.

[5] J. P. David, F. Floret, J. Guerin, J. C. Paiva, and L. Aiache, "Autonomous photovoltaic converter with linear focusing concentrator," Solar Cells, vol. 4, no. 1, pp. 61-70, 1981.

[6] M. Effendy Ya’Acob, H. Hizam, M. T. Htay, M. A. M. Radzi, T. Khatib, and M. Bakri A, "Calculating electrical and thermal characteristics of multiple PV array configurations installed in the tropics," Energy Conversion and Management, vol. 75, pp. 418-424, 2013.

[7] C. S. Solanki, C. S. Sangani, D. Gunashekar, and G. Antony, "Enhanced heat dissipation of V-trough PV modules for better performance," Solar Energy Materials and Solar Cells, vol. 92, no. 12, pp. 1634-1638, 2008.

[8] R. Tang and X. Liu, "Optical performance and design optimization of V-trough concentrators for photovoltaic applications," Solar Energy, vol. 85, no. 9, pp. 2154-2166, 2011.

[9] S. Riffat and A. Mayere, "Performance evaluation of v-trough solar concentrator for water desalination applications," Applied Thermal Engineering, vol. 50, no. 1, pp. 234-244, 2013.

[10] S. Maiti, S. Banerjee, K. Vyas, P. Patel, and P. K. Ghosh, "Self regulation of photovoltaic module temperature in V-trough using a metal-wax composite phase change matrix," Solar Energy, vol. 85, no. 9, pp. 1805-1816, 2011.

[11] K. K. Chong, K. G. Chay, and K. H. Chin, "Study of a solar water heater using stationary V-trough collector," Renewable Energy, vol. 39, no. 1, pp. 207-215, 2012.

[12] S. R. Wenham, M. A. Green, M. E. Watt, and R. Corkish, "The characteristics of sunlight," in Applied Photovoltaic, pp. 3-25, Earthscan Publication, London, UK, 2nd edition, 2007.

[13] K. E. Park, G. H. Kang, H. I. Kim, G. J. Yu, and J. T. Kim, "Analysis of thermal and electrical performance of semitransparent photovoltaic (PV) module," Energy, vol. 35, no. 6, pp. 2681-2687, 2010.

[14] J. P. Kim, H. Lim, J. H. Song, Y. J. Chang, and C. H. Jeon, "Numerical analysis on the thermal characteristics of photovoltaic module with ambient temperature variation," Solar Energy Materials and Solar Cells, vol. 95, no. 1, pp. 404-407, 2011.

[15] R. C. Sprinthall and S. T. Fisk, Basic Statistical Analysis, Prentice Hall, Englewood Cliffs, NJ, USA, 1990.

[16] D. C. Montgomery, G. C. Runger, and N. F. Hubele, Engineering Statistics, John Wiley \& Sons, New York, NY, USA, 2009.

[17] I. Mbamali, "An assessment of solar radiation patterns for sustainable implementation of solar home systems in nigeria," American International Journal of Contemporary Research, vol. 2, no. 6, 2012.

[18] J. Leloux, L. Narvarte, and D. Trebosc, "Review of the performance of residential PV systems in France," Renewable and Sustainable Energy Reviews, vol. 16, no. 2, pp. 1369-1376, 2012.

[19] D. Paul, D. Mukherjee, and S. R. B. Chaudhuri, "Assessing solar PV behavior under varying environmental conditionsa statistical approach," in Proceedings of the 4th International Conference on Electrical and Computer Engineering (ICECE'06), pp. 217-220, December 2006.
[20] G. Y. Obeng, H.-D. Evers, F. O. Akuffo, I. Braimah, and A. BrewHammond, "Solar photovoltaic electrification and rural energypoverty in Ghana," Energy for Sustainable Development, vol. 12, no. 1, pp. 43-54, 2008.

[21] A. H. Haris, "Grid-connected and building integrated photovoltaic: application status \& prospect for Malaysia," Master Builders Journal, vol. 3, pp. 91-95, 2006.

[22] A. Haris, MBIPV Project: Catalyzing Local PV Market, Finance \& Investment Forum on PV Technology, Kuala Lumpur, Malaysia, 2008. 

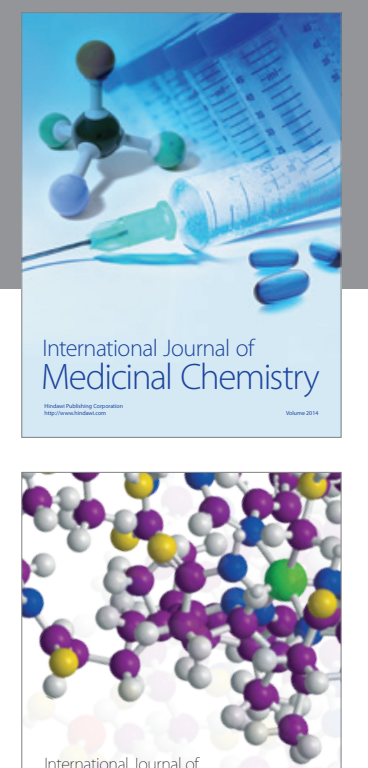

\section{Carbohydrate} Chemistry

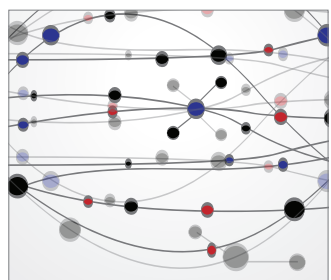

The Scientific World Journal
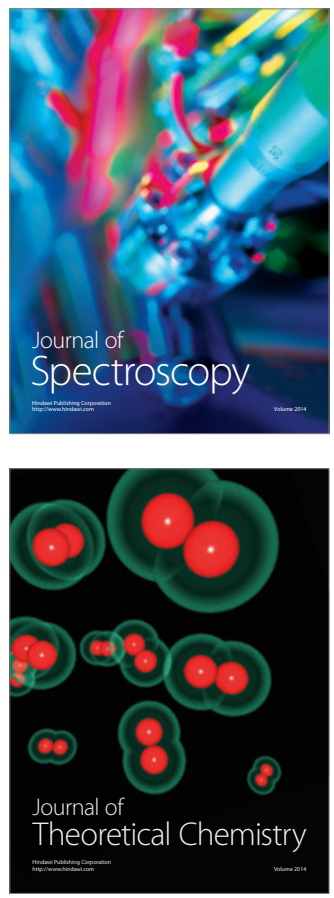
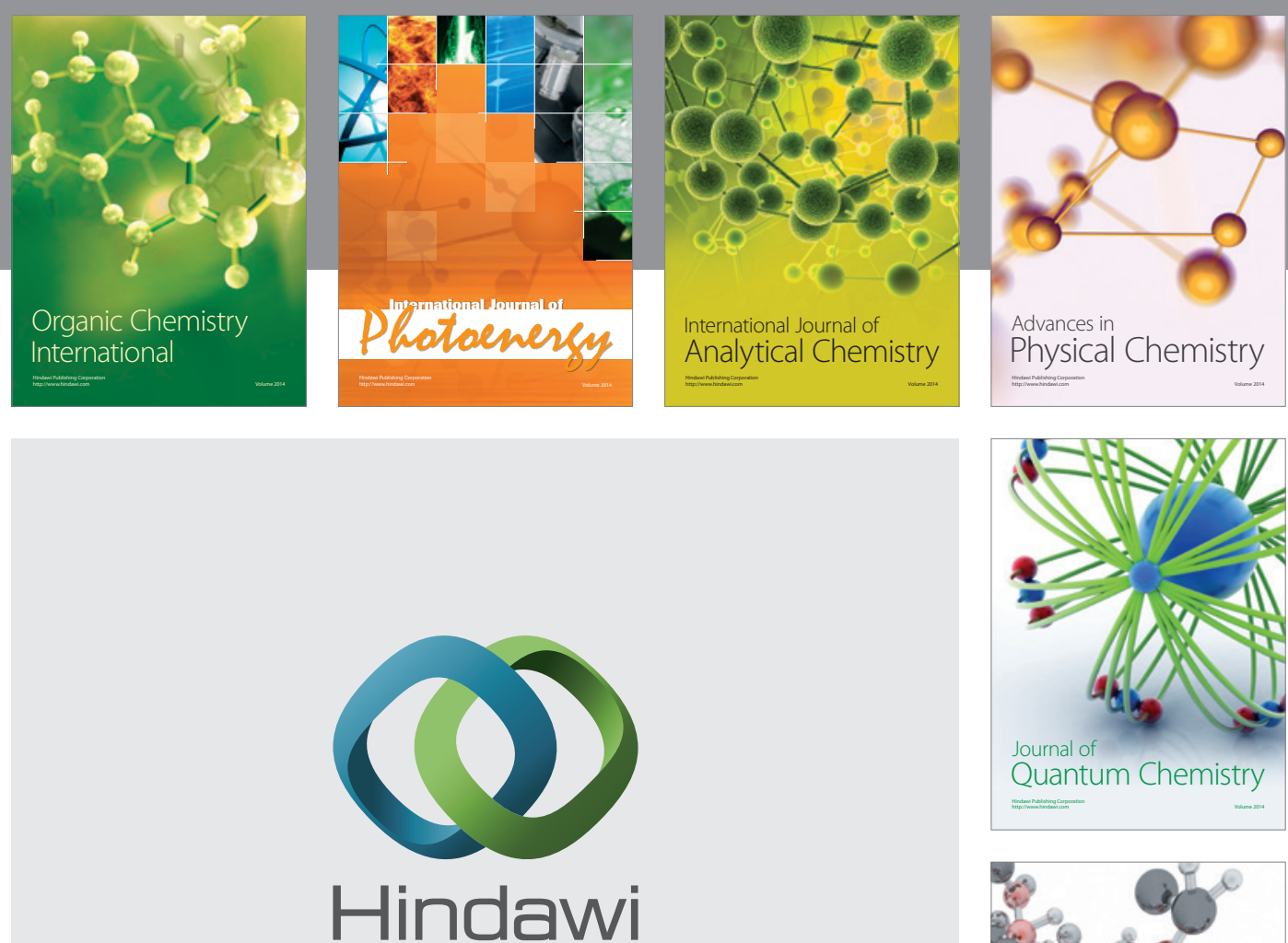

Submit your manuscripts at

http://www.hindawi.com

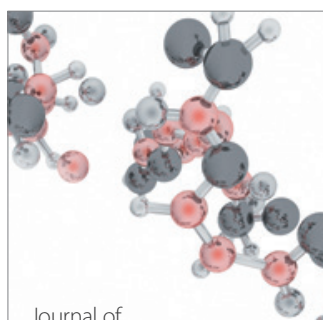

Analytical Methods

in Chemistry

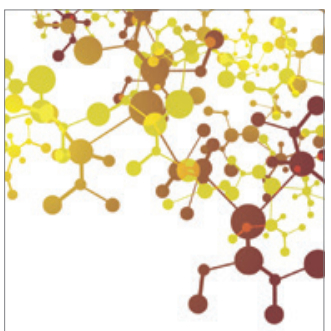

Journal of

Applied Chemistry

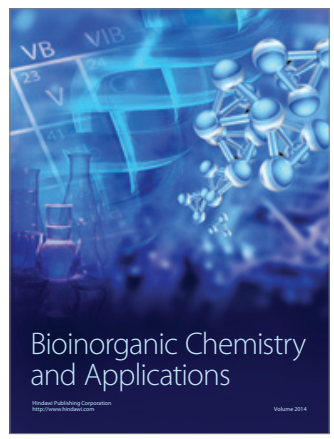

Inorganic Chemistry
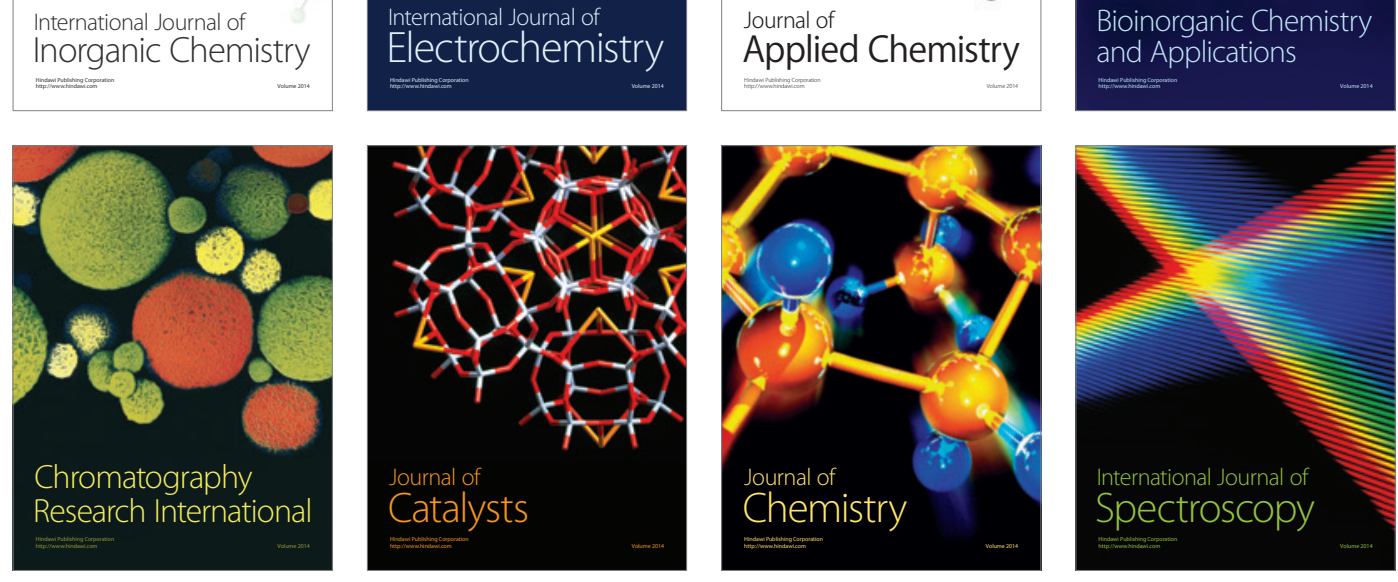